\title{
Forces and Motion: How Young Children Understand Causal Events
}

\author{
Tilbe Göksun \\ University of Pennsylvania
}

\author{
Nathan R. George and \\ Kathy Hirsh-Pasek \\ Temple University
}

\author{
Roberta M. Golinkoff \\ University of Delaware
}

\begin{abstract}
How do children evaluate complex causal events? This study investigates preschoolers' representation of force dynamics in causal scenes, asking whether (a) children understand how single and dual forces impact an object's movement and (b) this understanding varies across cause types (Cause, Enable, Prevent). Three-and-a half- to 5.5-year-olds $(n=60)$ played a board game in which they were asked to predict the endpoint of a ball being acted upon by one or two forces. Children mostly understood the interactions of forces underlying each type of cause; only 5.5-year-olds could integrate two contradictory forces. Children perceive force interactions underlying causal events, but some concepts might not be fully understood until later in childhood. This study provides a new way of thinking about causal relations.
\end{abstract}

Consider the everyday events of an ordinary playground: children throwing Frisbees, blocking soccer balls, and helping each other push their friends on the swing. Psychologists tend to describe these complex scenes with simple causal mechanisms (Michotte, 1963) or chains of simple causes (e.g., Baillargeon, 1994; Cohen, Rundell, Spellman, \& Cashon, 1999; Leslie, 1982, 1984; Oakes \& Cohen, 1990; Rakison \& Krogh, 2012; Saxe, Tenenbaum, \& Carey, 2005; Saxe, Tzelnic, \& Carey, 2007). In this article, we move beyond this simple Michottean causality and examine how children process complex causal scenes in light of force dynamics theory. Defined as the interaction between entities in space resulting from multiple forces (Talmy, 1988; Wolff, 2003, 2007), force dynamics encompasses not only simple cause-effect relations but also ways in which two or more forces

This work was supported by NICHD Grant 5R01HD050199 and by NSF Grant BCS-0642529 to the second and third authors. We thank everyone at the Temple University Infant Lab and in the Spatial Intelligence and Learning Center (particularly the RISC group at Temple University) for their invaluable contributions to this project. We also thank Nora Newcombe for helpful suggestions on many phases of this project. Special thanks to Kelly Fisher, Sarah Roseberry, Andrea Frick, Wendy Shallcross, Yannos Misitzis, Russell Richie, Katrina Ferrara, Carolyn Winslow, and Rhea Miles for their help in stimulus design, data collection, and coding. We are grateful to the children and parents who participated in the study.

Correspondence concerning this article should be addressed to Tilbe Göksun, Department of Neurology, University of Pennsylvania, 3400 Spruce Street, 3 Gates, Philadelphia, PA 19104. Electronic mail may be sent to tilbe@mail.med.penn.edu. can affect the trajectory of an entity in an event. Drawing on Wolff's $(2003,2007)$ force dynamics theory of causal language, we investigate the development of force dynamics representations in children and reconsider the psychologist's definition of causality given the complexity of the causal relations that constitute everyday events.

\section{Force Dynamics}

Until recently, force dynamics has been "a neglected field of study" (Talmy, 1988) in semantics, as well as in spatial understanding, event perception, and language development. Event perception research has traditionally emphasized the perception of causality from a Michottean perspective (Michotte, 1963), relying on direct causal events in which one object (i.e., agent) contacts a stationary object (i.e., patient), causing the patient to immediately move along the agent's trajectory while the agent ceases movement. The spatiotemporal contiguity between the two movements creates the perception of causality. Evidence for the primacy of spatiotemporal features in causal perception has yielded promising results with both adults (e.g., Choi \& Scholl, 2006; Fugelsang, Roser, Corballis, Gazzaniga, \& Dunbar,

(C) 2013 The Authors

Child Development (C) 2013 Society for Research in Child Development, Inc. All rights reserved. 0009-3920/2013/xxxx-xxxx

DOI: $10.1111 /$ cdev. 12035 
2005; Schlottmann, Ray, Mitchell, \& Demetriou, 2006) and infants (e.g., Carey, 2009; Cohen \& Amsel, 1998; Leslie \& Keeble, 1987; Muentener \& Carey, 2010; Newman, Choi, Wynn, \& Scholl, 2008; Oakes, 1994; Rakison \& Krogh, 2012; Saxe et al., 2005; Saxe et al., 2007; Shultz, 1982). Many have used such findings to support a mechanist account of causal perception, in which the transmission of some physical quantity (e.g., energy, momentum) is considered necessary and sufficient for the perception of causal interactions (see Shultz, 1982).

While such conclusions might reflect a valid part of causal knowledge, they are limited with respect to the full array of causal interactions. Other factors relevant to the interpretations of complex causal events have not been explained. For example, a vital component of a causal event, the spatial array of forces (e.g., the angle of an object's movement after collision), has recently been shown to be influential to causal perception in adults (Straube \& Chatterjee, 2010; Wolff, 2007). Moreover, previous research has focused primarily on one-force causal interactions, yet the environment often contains multiple kinetic forces working in concert. Extending the analysis of causality into these more complicated scenarios may reveal a greater range of development in these representations.

Building on work by Talmy $(1985,1988)$ and Jackendoff (1990), a recent theory addresses the limitations of previous mechanist accounts of causality (Wolff, 2003, 2007). The force dynamics model makes improvements on previous research by taking into account the multiple forces that underlie the full array of causal events. Force dynamics expands our view of cause, distinguishing among the types of cause: Cause (one force that moves an object), Enable (a secondary force that promotes motion in the intended direction), and Prevent (a secondary force that hinders motion in the intended direction; Wolff, 2003). (We choose "enable" rather than "help" to be in accord with the force dynamics literature; e.g., Sloman, Barbey, \& Hotaling, 2009; Wolff, 2003, 2007.) For example, when a boat is moving toward a port, a secondary force, "the wind," might prevent the boat from doing so by changing its direction. In contrast, if the boat were hit by a ship moving in the intended direction, the force of the ship would enable the boat to reach port. Wolff and colleagues found that adults correctly map causal verbs onto events through the identification of these three event classes (Cause, Enable, and Prevent), supporting the theory that causality has different category-level representations (Wolff, 2003, 2007; Wolff \& Song, 2003; Wolff, Song, \& Driscoll, 2002). It appears that these causal categories are codified in a number of languages. For example, Wolff, Klettke, Ventura, and Song (2005) showed that English, German, Russian, Spanish, and Arabic all use verbs to express Cause, Enable, and Prevent relations. The authors concluded that these expressions of causal relations are not unique to English. Here, we borrow Wolff's terminology of the force dynamics of causal language and adjust it to assess preschool children's perception of forces and their interactions in complex causal scenes.

\section{Understanding an Object's Trajectory and Integrating Forces in Childhood}

Infants in their 1st year of life expect motion events to have causes (e.g., Harding \& Golinkoff, 1979) and have some knowledge of an object's trajectory in such events, even when a portion of the object's path is occluded (Johnson et al., 2003; Kotovsky \& Baillargeon, 2000; Muentener \& Carey, 2010; Spelke, Philips, \& Woodward, 1995). Yet preschool children often have misconceptions about the trajectories of an object's motion when causal forces are combined. For example, 4.5- to 5.5-year-old children predicted a straight path rather than a parabolic trajectory when asked to combine momentum and gravity to judge the path of a ball rolling off a table or dropping from a moving train (Kaiser, McCloskey, \& Proffitt, 1986; Kaiser, Proffitt, \& McCloskey, 1985; but see Hood, 1995, 1998). Moreover, research has shown that even older children have trouble integrating forces to estimate the movement of an object and consequently the result of an event. For example, Pauen (1996) presented elementary schoolchildren (ages between 6 and 10 years) a task in which two forces acted on a target object. The target object was fixed at the center of a circular platform, surrounded by a barrier with an opening. This barrier could be rotated around the platform. Each force was represented by different number of weights resting on small plates connected to the target object by separate cords. In each trial, the experimenter manipulated the number of weights on the plates (magnitude) and the angle between the cords (direction). Children were asked to rotate the barrier to position the opening such that the target would slide through it. Results showed that children younger than 10 years of age seemed to ignore one aspect of the vectors - either magnitude or direction. One intriguing exception is preschool children's reasoning about the path of a ball exiting a curved tube. Five-year-olds correctly solve this common physics problem, predicting a straight path for the ball; however, following entry into school, children begin attributing 
a curved path to the ball, suggesting that such early reasoning is not the robust, sophisticated reasoning seen in adults (Kaiser et al., 1986). Such fallacies about the relations between force and motion persist even into high school (e.g., McDermott \& Redish, 1999; Roth, 1990).

To this point, research on force dynamics in childhood has mostly been restricted to knowledge of intuitive physics and nonverbal causal reasoning (for a review, see Wilkening \& Cacchione, 2011). However, there is value in also examining how force dynamics is manifested both in event representations and in the corresponding semantic categories of language that both go beyond simplistic pictures of causality. Recent evidence suggests that before producing motion verbs such as cross or jump, children detect the components of motion events (e.g., the trajectory of the movement, the figure of the action, the manner of the figure). That is, they acquire the necessary conceptual basis before they lexicalize different types of events in languages (Göksun, Hirsh-Pasek, \& Golinkoff, 2010b). Similar conclusions can be drawn about the development of simple causal language.

As Wolff et al. (2005) suggested, many languages represent these complex events in their causal language system. Developmental research has shown that children start using causal verbs such as break and cut in the 2nd year of life, but it is not until age 4 years that they reliably use causal verbs and other causal connectives to describe causal relations (Bowerman, 1974; Clark, 2003; Göksun, Hirsh-Pasek, \& Golinkoff, 2010a). Interestingly, 4- and 5-year-olds rely on gestures to supplement their speech before they form complete causal sentences. For example, these children represent the instrument of a causal relation only in gesture without mentioning it in speech (Göksun et al., 2010a). Thus, the productive use of causal language lags behind the understanding of simple causes.

According to one view, learning to use different types of causal verbs (Cause, Enable, and Prevent) to talk about causal scenes that integrate various forces requires that children understand complex causal events. Wolff's (2007) study with adults suggests some characteristics that these representations may contain. His research has shown that the representations of force dynamics underlying language encode both the direction and the magnitude of forces working in concert. Alternatively, exposure to verbs that encode Cause, Enable, and Prevent, may encourage children to attend to complex, multiforce events. In other words, although simple causal language may be based on early concepts, learning causal language might help children to move from this basic understanding of causal relations to force dynamic representations (for arguments on a different domain-learning number words and counting, see Lipton \& Spelke, 2005). Thus, the examination of children's understanding of multiple force events sets the stage for determining whether these representations are precursors to force dynamics verbs or whether these semantic categories enhance children's representations of these events.

\section{The Current Study}

Force dynamics defines different classes of causal events and verbs according to different patterns of forces. To make these distinctions among causal events, children must be able to combine and integrate multiple forces. The current state of the field is not clear on whether young children can combine and integrate multiple forces before they productively talk about complex causal relations (Clark, 2003). This study examines how preschoolers evaluate multiple forces and process events in terms of force dynamics. We ask three questions: First, do children between 3.5 and 5.5 years of age understand the impact of one and two forces on an object's movement and its endpoint? Based on the findings of Pauen (1996), we hypothesize that younger children might be unable to integrate two forces to predict the movement of an object. Second, are children's predictions equally accurate among the different types of cause (Cause, Enable, Prevent)? We predict that children might represent Cause and Enable relations earlier than Prevent relations, because Prevent involves two contradictory forces. Finally, what types of errors do children make when trying to integrate forces? We analyze children's errors for each categorical representation to see whether children perseverate on a single force, despite the presence of other forces.

\section{Method}

\section{Participants}

The final sample consisted of 60 monolingual English-speaking children, balanced for gender and evenly separated into three age groups: 3.5-yearolds $(M=44.64$ months, $S D=2.67$, range $=40.02$ 48.08 months $), \quad 4.5$-year-olds $(M=54.95$ months, $S D=3.94$, range $=49.06-60.21$ months $)$, and 5.5year-olds $(M=64.86$ months, $S D=2.36$, range $=$ 
61.17-71.0 months). Children were predominantly White and of middle-class families from a Northeastern city in the United States. Based on prior research on children's understandings of other physical problems (e.g., Kim \& Spelke, 1999), and children's effective use of causal language (e.g., Göksun et al., 2010a), these age groups were chosen to represent the complete developmental trajectory for force dynamics. Additional data from five 3.5-year-olds and one 4.5-year-old were excluded from analysis due to failure to respond during the task (six). In addition, data from one child from each of the older groups were discarded due to experimenter error (two). Finally, nine adults $(M=28.77$ years, $S D=4.91$ ) were recruited to assess adults' performance on this novel task.

\section{Materials}

Children's understanding of causal relations was examined through an interactive board game. The game board $(180 \mathrm{~cm} \times 180 \mathrm{~cm})$ was made of a green felt mat and divided into a $6 \times 6$ grid of $30 \mathrm{~cm} \times 30 \mathrm{~cm}$ squares using masking tape (see Figure 1). A 1.5-in. diameter curved plastic tube (16 in. tall $\times 5$ in. deep) was inserted into a model house so that it entered into the roof and exited out from the front. In all conditions, the first force was provided by the motion of a small foam ball exiting the tube. In Enable and Prevent relations, the hairdryer's "wind" was used as a secondary force. There were also four colored felt squares $(30 \mathrm{~cm} \times 30 \mathrm{~cm})$. The child was asked to choose the one they liked for marking the final location of the ball. The board was laid on the ground in a quiet room where each child was tested individually. A camera recorded the session for later coding.

\section{Procedure}

The experiment consisted of two test phases (oneand two-force trials). Each test phase started with a practice trial. The order of the phases (one- and two-force trials) remained constant among children.

One-force trials: Practice trial. First, the experimenter presented the task materials and described the game to the child (see Figure 1, top row). Next, the experimenter asked the child to pick her favorite colored square and explained the child's role in the game: "The goal of the game is to guess where the ball will stop. You are the player and will guess where the ball goes and stops on these squares." Then, the house was put on one of the board's grid squares, with the end of the tube in line with the edge of the next square. The experimenter drew the child's attention to the tube saying, "Wow, do you see the long chimney and how it goes through the house and comes out the side?" Finally, the experimenter took the ball and held it over the top of the tube, asking the child where she thought the ball would exit and how far it would travel. After the child put the colored square on the felt mat, the experimenter said, "Watch what happens when I drop the ball from here (the top of the tube). Did you see how it goes? See how it came out from here (showing the curved part of the tube - the door of the house)?" Next, the experimenter asked the child to drop the ball from the tube so that the child was familiar with the procedure and the weight of the ball.

After being familiarized with the task materials, the experimenter placed the house on a different square and asked the same question as before, now requiring the child to put the colored square (the same size as one of the grid squares) on the grid square where she thought the ball would land. The child was permitted to place the colored square anywhere, including locations off the board, although such responses were not encouraged from the outset. The child was asked to step aside and told to watch where the ball stopped. The experimenter dropped the ball from the chimney and the ball stopped on the board. If the child was incorrect, the experimenter would encourage the child to try again and would repeat the action one more time. The practice trial ensured that the child was familiar with the materials and attuned to the movement of the ball with one force. If a child failed in the second practice trial, the experimenter explained the procedure one more time and ensured that the child understood the task by asking the child to point at the end state of the ball.

One-force trials: Test trials. Phase 1 of the test contained three simple Cause trials, in which the experimenter was the only cause of the action (oneforce trials). The house was placed in different positions and turned in either horizontal or diagonal directions as shown in Figure 1. By manipulating the orientation of the house, we examined whether children's integration of forces was dependent on any specific spatial orientation. The child either received two horizontal trials and one diagonal trial or two diagonal trials and one horizontal trial in a counterbalanced order. For each location, the child made a prediction using the colored square and the experimenter dropped the ball through the tube.

Two-force trials: Practice trial. This phase started by introducing the child to the workings of the hairdryer that served as the second force (i.e., the wind) on the ball. The child felt the "wind" by 
Set-up and Materials for the Study
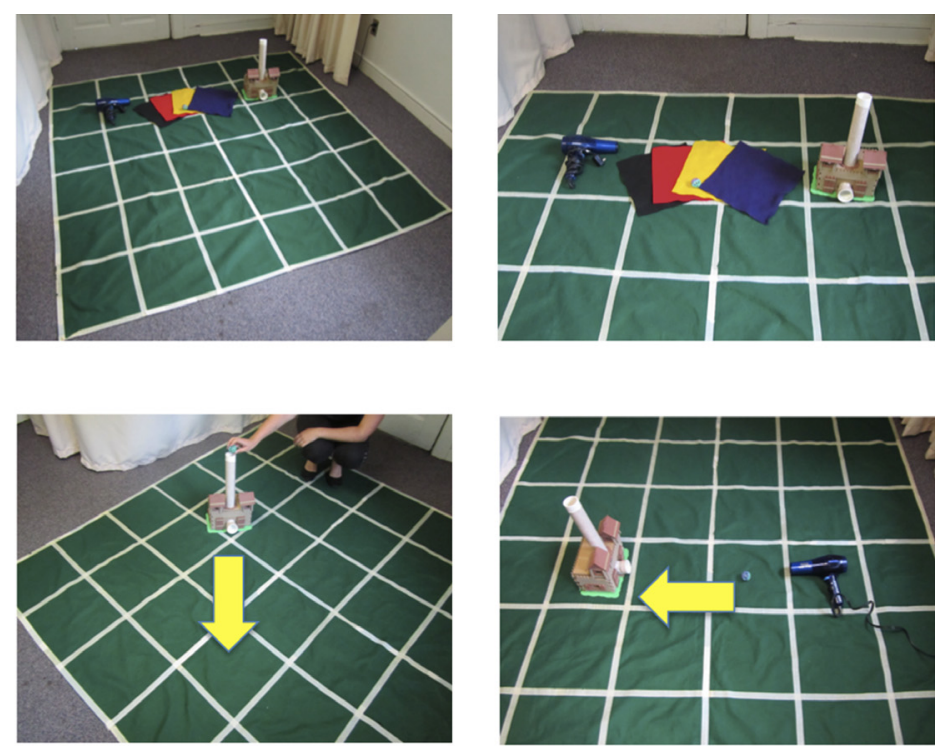

Sample CAUSE Trials
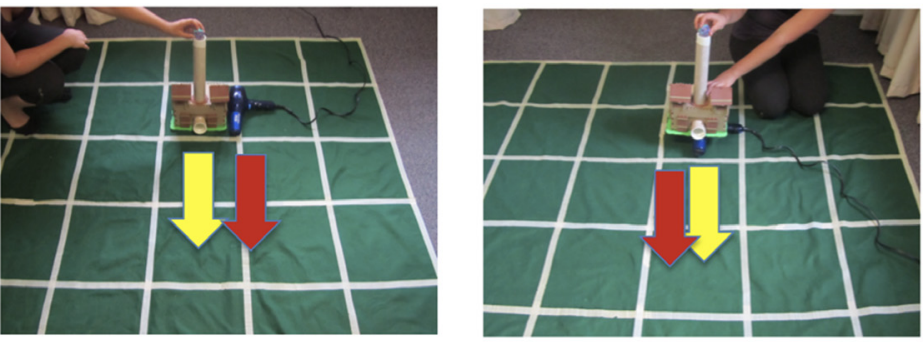

Sample ENABLE Trials
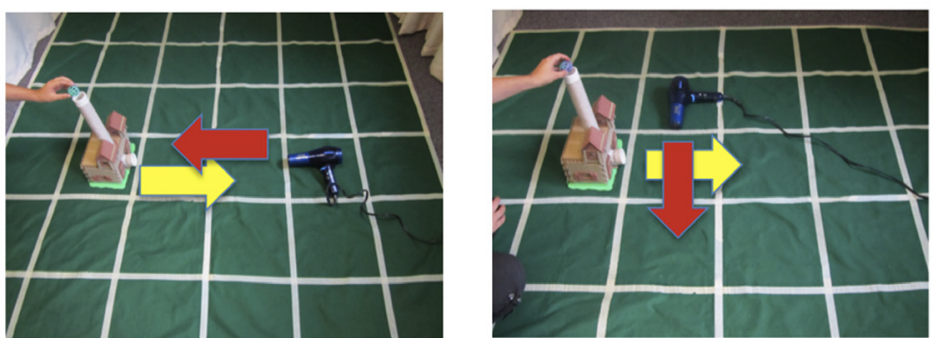

Figure 1. The board game setup with the model house, hairdryer, and materials (top row) and sample Cause, Enable, and Prevent trials (one- and two-force trials). The yellow arrows represent the direction of the ball exiting the model house (initial force) and the red arrows represent the direction of the hairdryer (secondary force). In prevent trials, the left picture is the "opposing" Prevent and the right picture is the "perpendicular" Prevent. See the online version of this article for Figure 1 in color.

turning the hairdryer on and placing his or her hand close to the opening. Then, the experimenter put the ball in front of the hairdryer on the mat and turned the hairdryer on to show the child that the wind from the hairdryer moved the ball on the mat. After this introduction and ensuring that the child was still engaged in the game, the house and the hairdryer were positioned on the board for a practice trial. The hairdryer was lined up flush to the middle of the left edge of the square in front $(15 \mathrm{~cm})$ of the fort, with the wind blowing across the front of the house. The experimenter turned on the hairdryer and then rested his hand on top of the tube. Then, the child was asked where the ball would land and to put his or her colored square on the grid. After the child placed his or her colored square, the experimenter dropped the ball through the tube. The child was again asked to step aside and told to watch where the ball stopped. If a child was incorrect, the experimenter would encourage the child to try again and repeat the action one more time. The experimenter always ensured that the child followed where the ball landed by asking the child to point at the end state of the ball. In this 
second practice trial for two forces, the experimenter confirmed that the child saw the movement of the ball with the second force.

Two-force trials: Test trials. One Cause trial with the hairdryer, two Enable trials, and two Prevent trials were presented in a counterbalanced order using the same script as above. In the new Cause trial, the hairdryer was located two squares in front of the house $(60 \mathrm{~cm})$ and pointed back toward the house (in this case the hairdryer is the Cause). Both the edge of the tube and the end of the hairdryer were lined up centered and flush with the edge of a grid square. The ball was put in the center of the square directly in front of the hairdryer $(15 \mathrm{~cm})$ and the child was asked to predict the endpoint of the ball when only the hairdryer acted upon it.

In Enable trials, the house was placed flush with the edge of a grid square and the hairdryer was either placed next to the house $(15 \mathrm{~cm}$ from center of tube to center of hairdryer) or under the house (the center of the tube $10 \mathrm{~cm}$ above the center of the hairdryer). The ball exiting the house was propelled along its initial line of motion by the hairdryer in either case. Each child received one diagonal and one horizontal trial.

In Prevent trials, the ball's motion upon exiting the house was precluded by the hairdryer, located either opposite the house ("opposing Prevent") or perpendicular to the house ("perpendicular Prevent"). In the opposing Prevent, the hairdryer was two squares in front of the house $(60 \mathrm{~cm})$ facing back toward the house. In perpendicular prevent trials, the hairdryer was lined up flush to the middle of the left edge of the square in front $(15 \mathrm{~cm})$ of the fort, with the wind blowing across the front of the tube. These relations were both classified as Prevent because they prevented the ball from continuing on its original of motion. In the Enable and Prevent trials, both the experimenter and the hairdryer were forces acting upon the ball (two-force trials; see Figure 1 for sample trials).

\section{Coding and Reliability}

The accuracy of children's responses was coded for each trial. To count as correct, children's predictions for both the ball's direction and endpoint were considered. Figure 2 presents the correct and incorrect responses in each trial. For example, a horizontal Cause trial was counted as correct if the child guessed that the ball would stop on the board right in front of the house. That is, a correct response included the prediction that the ball would stop on the first or second grid square in front of the house, as was seen by the child in the warm-up trial. A correct answer in the horizontal Enable trial included the prediction that the ball's endpoint was at least the third grid square from the house, indicating recognition that the additional force should propel the ball farther than in Cause trials. For the perpendicular Prevent trial in which the hairdryer was located perpendicular to the house, the child's guess should have been $45^{\circ}$ to the right of the ball's original path. For the opposing Prevent trial, the correct answer should be the grid square directly in front of the house. Although correct responses varied by trial in the number of squares that are considered correct, we believed any resulting bias is minimal. Specifically, the nature of the scheme was categorical, not exact, and so whether the category of "farther than the cause trial" or "shorter than the cause trial" contained one, two, or three possible locations should be of minimal importance. Finally, we coded children's exact predicted square in relation to the house.

Children's errors were classified into different types based on the trial. For Cause trials, an error was scored as "no straight path" if the child does not take the ball's straight motion into account (e.g., predicting the ball would turn sharply left or right) or other (e.g., predicting an area outside the board). For Enable trials, the errors were divided into two types: "no straight path" as before or "no wind's force" if the child does not take the wind's force into account (i.e., not predicting an endpoint beyond the Cause trial result). For Prevent trials, the errors could be related to either the straight path or the wind's force, or both.

To obtain intercoder reliability, $20 \%$ of children were coded by a second person who was blind to the task. Agreement between coders was 96\% $(k=.94, n=96)$.

\section{Results}

\section{Preliminary Analyses}

First, we analyzed adults' correct predictions to one- and two-force trials. Paired-sampled $t$ tests showed that adults' responses $\left(M_{\text {one-force }}=100\right.$ and $M_{\text {two-force }}=88.90$ ) were at ceiling for one-force trials and almost at ceiling for two-force trials, yielding no significant difference between trial types, $t(8)=1.84$, $p>$.05. Further analysis indicated no reliable differences between Enable and Prevent trials, $p>.05$ $\left(M_{\text {Enable }}=88.90\right.$ and $\left.M_{\text {Prevent }}=88.90\right)$. Thus, these results suggest that adults could judge the direction and endpoint of both one- and two-force trials, successfully integrating two forces in this novel task. 

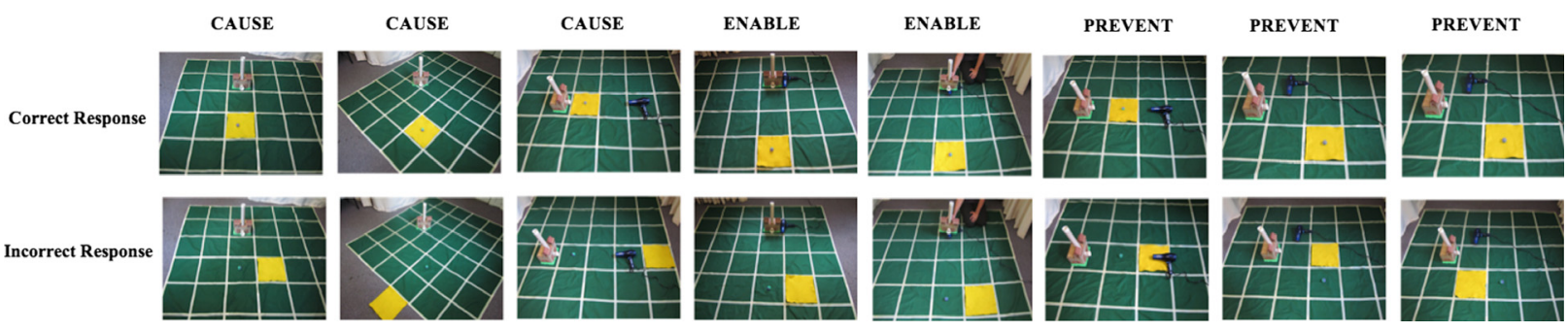

Figure 2. Sample correct and incorrect responses from a set of trials in the task. The yellow square in each trial demonstrates a child's choice. See the online version of this article for Figure 2 in color.

Second, a repeated measure analysis of variance (ANOVA) with age (3.5-, 4.5-, and 5.5-year-olds) and gender as between-subject variables, and causal type (Cause, Enable, Prevent) as a within-subject variable indicated no significant main effect of gender or any interactions with gender. Thus, gender was not considered in further analyses.

\section{Predictions in One- and Two-Force Trials}

Children's mean percentage of correct responses to one- and two-force trials was analyzed using a repeated measure ANOVA with age (3.5-, 4.5-, and 5.5-year-olds) as a between-subject variable, and trial type (one- vs. two-force) as a within-subject variable. Results yielded significant main effects of age and trial type as well as an Age $\times$ Trial Type interaction, $F(1,57)=44.09, p<.01, \eta_{\mathrm{p}}{ }^{2}=.34 ; F(2$, $57)=4.69, p<.01, \eta_{\mathrm{p}}^{2}=.14 ;$ and $F(2,57)=3.92$, $p<.05, \eta_{\mathrm{p}}^{2}=.12$, respectively. As shown in Figure 3, post hoc analyses indicated that 5.5-yearolds gave reliably more correct responses than 3.5- and 4.5-year-olds only in two-force trials (Scheffé, $p \mathrm{~s}<.03)$. Further pair-sampled $t$ tests indicated that 5.5-year-olds were not significantly different from adults in their predictions of one-force or two-force trials, $t(27)=1.75, p>.05$ and $t(27)=2.63, p>.05$, respectively.

Next we analyzed whether the orientation of the model house in relation to the board (horizontal vs. diagonal) affected children's responses for oneversus two-force trials. For both types of trials, children in all age groups responded significantly better in horizontal directions, $t(59)=3.35, p<.05$, and $t(59)=2.56, p<.05$, respectively (one-force: $M_{\text {horizontal }}=93 \%$ and $M_{\text {diagonal }}=73 \%$ and twoforce: $M_{\text {horizontal }}=68 \%$ and $M_{\text {diagonal }}=53 \%$ ).

\section{Predictions in Cause, Enable, Prevent}

Children's responses to different cause types (Cause, Enable, Prevent) showed main effects of

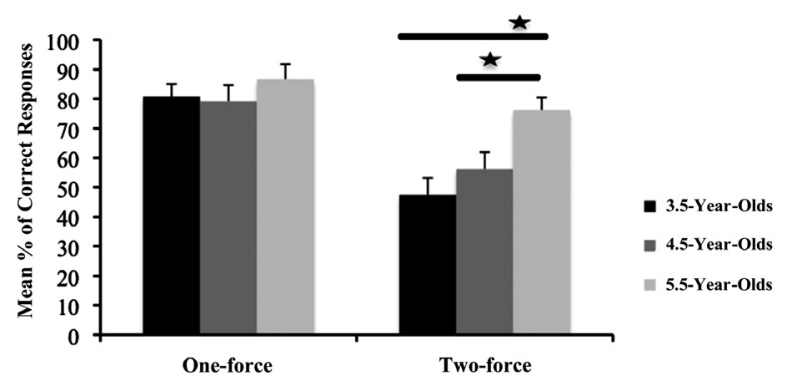

Figure 3. Mean percentages of children's correct responses to one-force and two-force trials. The error bars present the standard errors of the means.

$* p<.05$.

age and cause type, $F(2,57)=6.28, p<.01$, $\eta_{\mathrm{p}}{ }^{2}=.32$, and $F(2,114)=28.57, p<.01, \eta_{\mathrm{p}}{ }^{2}=.21$. No interaction between age and cause type was found (see Figure 4). Overall, 5.5-year-olds were better than both 3.5- and 4.5-year-olds in predicting the correct direction and endpoint of the ball in all types of trials (Scheffé, ps $<.05$ ). A further analysis indicated that 5.5-year-olds were not significantly different from adults, except in the Prevent trials, $t(27)=2.10, p<.05$. Children in all age groups were better at predicting the results of Cause compared to Enable and Prevent trials, $t(59)=2.053$, $p<.05$, and $t(59)=7.63, p<.05$, for Cause-Enable and Cause-Prevent comparisons, respectively. However, results of Enable trials seemed easier to

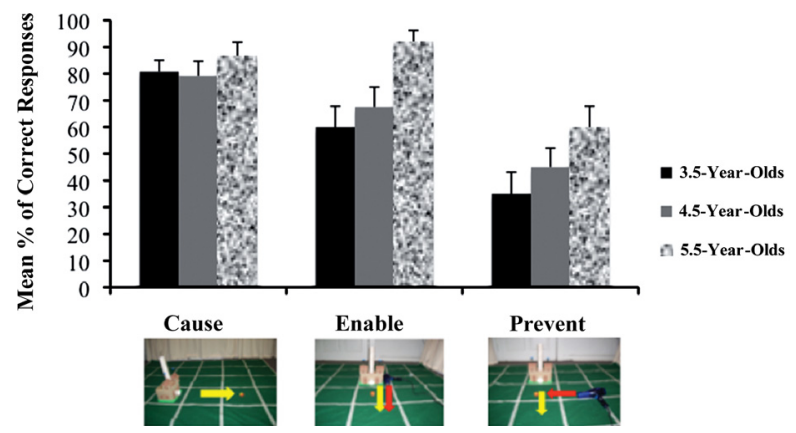

Figure 4. Mean percentages of children's correct responses to Cause, Enable, and Prevent relations. 
predict than Prevent trials for both horizontal and diagonal orientations of the model house, $t(59)$ $=3.09, p<.05$, and $t(59)=3.43, p<.05$ (Enable: $M_{\text {horizontal }}=80 \%$ and $M_{\text {diagonal }}=67 \%$ and Prevent: $M_{\text {horizontal }}=55 \%$ and $M_{\text {diagonal }}=38 \%$ ). Moreover, children in all age groups found the perpendicular Prevent trial harder than the opposing Prevent trial, $t(59)=3.59, \quad p=.01 \quad\left(M_{\text {perpendicular }}=34 \% \quad\right.$ and $M_{\text {opposing }}=62 \%$ ). Finally, we analyzed children's exact prediction location for Cause and Enable events. Results indicated that regardless of the age group, children added the wind's force in Enable trials and predicted a location further away from the house than in Cause trials, $F(1,52)=79.71$, $p<.0001, \eta_{\mathrm{p}}^{2}=.61$.

\section{Errors in Prediction}

When children erred in the Cause trials they did not consider that the ball should move in a straight path after being dropped into the tube. For Enable relations, younger children made similar prediction errors not taking the straight path into account. Nevertheless, the very few errors 5.5-year-olds made for Enable relations were the result of discounting the second force (the wind) on the ball's motion. That is, although these children predicted the path correctly, they placed the colored square on the first square in front of the house instead of farther out. Finally, children in all age groups rarely accounted for the second force (i.e., the wind) and perseverated on the person's force on the ball's motion for Prevent. Adults made very few errors in the Prevent and Enable relations and all were the result of only taking the second force into account.

\section{Discussion}

This study is among the first to go beyond children's understanding of simple cause and ask how they might integrate the intertwined effects of multiple causal forces. Following Wolff's theory of force dynamics, we asked preschool-aged children to predict the direction and endpoint of an object in three types of causal relations (Cause, Enable, and Prevent) that constitute the basis for the force dynamics model. Overall, results suggested that to some extent children represent force dynamics in causal events. We found that: (a) children were better at judging the direction and endpoint of one-force trials, with only 5.5-year-olds able to integrate two forces; (b) children at all ages were poorest with Prevent trials; and (c) children disregarded the secondary force (i.e., wind) when judging the endpoint of two-force interactions.
To some extent, children's knowledge of causal events extends beyond simple collisions among physical objects to a range of possible agents working in concert. The number and direction of forces in causal relations are crucial in predicting the goal of the action. The current study shows that while children are good at reasoning about one-force causal events, they are selectively attentive to secondary forces, incorporating them only if both forces move in the same direction. This characteristic of children's reasoning reflects their first, simplified rule for integrating forces. Prior research suggests that when asked to judge a rectangle's area, 3- and 4-year-olds use an additive integration rule (adding the height and width of a rectangle) rather than multiplying them (Cuneo, 1982; see also Schlottmann \& Anderson, 1994; Wilkening, 1981; but see Siegler's (1976) work on balance-beam problems). In addition to these studies, our study suggests that contrary to Piaget's notion of centration (Piaget, 1955), preschoolers can focus on two dimensions of a task using the additive integration rule. Indeed, only 5.5-year-olds developed beyond this additive strategy predicting the endpoint of the ball for some, but not all, of the two-force relations. They are not yet at adult levels when forces oppose one another.

The results of the Prevent trials shed light on the factors that influence force integration in childhood. In particular, the perpendicular Prevent relations were very difficult for preschool children, likely because the secondary force is at a $90^{\circ}$ angle from the initial force. In contrast, when the Prevent event is similar to the Enable one (i.e., when two forces interact by working in the same, singular dimension), children make fewer erroneous predictions. It seems likely, therefore, that the number of dimensions involved in multiple force interactions is an important factor in prediction above and beyond the concordance of forces. This may represent the most difficult hurdle to overcome in the current task.

Previous research demonstrates that children have similar misconceptions in other domains (for a review, see Wilkening \& Cacchione, 2011). For example, 4-year-olds have difficulty combining gravity and inertia when predicting where a ball would land after it rolled from a slightly downward slanted ramp. These children predict that the ball would descend in a straight path whereas 6-year-olds correctly predict the ball's parabolic path (Kim \& Spelke, 1999). Hood (1995) presented children with a vertical invisible displacement task, in which they were asked to 
find a ball dropped down one of the chimneys connected to three hiding boxes. Before 3 years of age, children did not take the trajectory of the tubes into account and searched for the ball in the box that was directly connected to the chimney where the ball was dropped. In tasks that require the calculation of different dimensions of vectors (weight and angle), even 9- and 10-yearolds have difficulty integrating dimensions (Pauen, 1996). Taken together, our findings provide converging evidence that before age 5 , children might perseverate on a single dimension when predicting the direction of an object's movement. Only after this age do they start considering the second dimension in certain contexts. Thus, children's conceptions about different variables in physical reasoning (gravity and inertia, integration of dimensions of vectors, and force dynamics) might not emerge until the later elementary school years.

These findings might also reflect an ongoing developmental trajectory in other cognitive domains such as memory and spatial reasoning. Our task not only requires children to integrate vectors and reason about causality but also to store different dimensions in memory and to consider the spatial orientation of the model house (horizontal vs. diagonal). Results from the orientation of the house show that children have difficulty with the diagonal task, possibly related to their emerging spatial reasoning and memory capacity. However, spatial reasoning per se may not be the problem. Children as young as 2 years of age remember the locations of several hidden objects sequentially (Sluzenski, Newcombe, \& Satlow, 2004) and found the location of an object when hidden at one location in a circular enclosure (Balcomb, Newcombe, \& Ferrara, 2011). Future studies should tease apart the role of these cognitive abilities in evaluating force dynamics among preschoolers.

Caution is required in interpreting the current findings. One question of interest is whether children at this age have enough experience with wind as conveyed by a hair dryer. Informal discussions with parents suggested that the children had experiences with hairdryers and that this was not an issue, but a more systematic investigation is warranted. In addition, in the beginning of the twoforce trials, we assured that children felt the wind by turning the hairdryer on and placing their hands close to the opening. Even with these assurances, however, we do not know whether another type of a second force (e.g., another ball) would lead to similar predictions.
Second, for this study, we chose to employ a board game task involving predictions, a rather stringent test of force dynamics. The possibility remains that preschoolers have a basic knowledge of even complex interactions that was not captured by the strict measures employed. Future experiments that present choices for the endpoint of the ball (e.g., will the ball stop on this square or this square?), and do not require children to generate a response, may further enhance our understanding of the state of preschoolers' knowledge of force dynamics.

Finally, our results hint at the relation between causal concepts and children's learning of complex causal language. Prior research shows that children do not productively use a full cadre of causal verbs to describe causal actions before ages 4-5 (Bowerman, 1974; Clark, 2003; Göksun et al., 2010a). To use different force dynamics verbs (e.g., Cause: cause, make, set; Enable: help, allow, let; Prevent: block, stop, keep), children might first need to differentiate and conceptualize various causal events represented by force dynamics. Nevertheless, the use of various force dynamics verbs might also direct children's attention to relevant characteristics of multiple force interactions. That is, language might be a flashlight on force dynamics and might help children form categories of force dynamics in much the same way that number words helps children organize their understanding of counting (e.g., Lipton \& Spelke, 2005). Either way, we expect a tight link between the causal events that children reason about and the events that they readily describe using force dynamics verbs. Future studies should examine how and at what age children encode these differences in their linguistic descriptions of events, and the nature of the relation between linguistic and nonlinguistic force dynamics representations.

In conclusion, our findings provide evidence about how preschoolers use force and motion to evaluate the causal relations they witness. Complex causal relations involving the interaction of forces are difficult to interpret before 5 years of age. Finally, this research opens an avenue to examine the relation between children's understanding of force dynamics and their use of a variety of causal verbs in language.

\section{References}

Baillargeon, R. (1994). How do infants learn about the physical world? Current Directions in Psychological Science, 3, 133-140. doi:10.1111/j.2044-835X.1994. tb00616.x 
Balcomb, F., Newcombe, N. S., \& Ferrara, K. (2011). Finding where and saying where: Developmental relationships between place learning and language in the second year. Journal of Cognition and Development, 12, 315-331. doi:10.1080/15248372.2010.544692

Bowerman, M. (1974). Learning the structure of causative verbs: A study in the relationship of cognitive, semantic and syntactic development. Papers and Reports on Child Language Development, 8, 142-178.

Carey, S. (2009). The origin of concepts. New York: Oxford University Press.

Choi, H., \& Scholl, B. J. (2006). Perceiving causality after the fact: Postdiction in the temporal dynamics of causal perception. Perception, 35, 385-399. doi:10.1068/p5462

Clark, E. V. (2003). First language acquisition. New York: Cambridge University Press.

Cohen, L. B., \& Amsel, G. (1998). Precursors to infants' perception of causality. Infant Behavior and Development, 21, 713-731. doi:10.1016/S0163-6383(98)90040-6

Cohen, L. B., Rundell, L. J., Spellman, B. A., \& Cashon, C. H. (1999). Infants' perception of causal chains. Psychological Science, 10, 412-418. doi:10.1111/1467-9280.00178

Cuneo, D. O. (1982). Children's judgments of numerical quantity: A new view of early quantification. Cognitive Psychology, 14, 13-41018-1029. doi:10.1016/0010-0285(82)90003-2

Fugelsang, J. A., Roser, M. E., Corballis, P. M., Gazzaniga, M. S., \& Dunbar, K. N. (2005). Brain mechanisms underlying perceptual causality. Cognitive Brain Research, 24, 41-47. doi:10.1016/j.cogbrainres.2004.12.001

Göksun, T., Hirsh-Pasek, K., \& Golinkoff, R. M. (2010a). How do preschoolers express cause in gesture and speech? Cognitive Development, 25, 56-68. doi:10.1016/ j.cogdev.2009.11.001

Göksun, T., Hirsh-Pasek, K., \& Golinkoff, R. M. (2010b). Trading spaces: Carving up events for learning language. Perspectives on Psychological Science, 5, 33-42. doi:10.1177/1745691609356783

Harding, C. G., \& Golinkoff, R. M. (1979). The origins of intentional vocalizations in prelinguistic infants. Child Development, 50, 33-40.

Hood, B. M. (1995). Gravity rules for 2-4 year-olds? Cognitive Development, 10, 577-598. doi:10.1016/0885-2014 (95)90027-6

Hood, B. M. (1998). Gravity does rule for falling events. Developmental Science, 1, 59-63. doi:10.1111/1467-7687.00013

Jackendoff, R. (1990). Semantic structures. Cambridge, MA: MIT Press.

Johnson, S. P., Bremner, J. G., Slater, A., Mason, U., Foster, K., \& Cheshire, A. (2003). Infants' perception of object trajectories. Child Development, 74, 94-108. doi:10.1111/ 1467-8624.00523

Kaiser, M. K., McCloskey, M., \& Proffitt, D. R. (1986). Development of intuitive theories of motion in the absence of external forces. Developmental Psychology, 22, 67-71. doi:10.1037/0012-1649.22.1.67

Kaiser, M., Proffitt, D. R., \& McCloskey, M. (1985). The development of beliefs about falling objects. Perception E Psychophysics, 38, 533-539. doi:10.3758/BF03207062
Kim, I. K., \& Spelke, E. S. (1999). Perception and understanding of effects of gravity and inertia on object motion. Developmental Science, 2, 339-362. doi:10.1111/ 1467-7687.00080

Kotovsky, L., \& Baillargeon, R. (2000). Reasoning about collisions involving inert objects in 7.5-month-old infants. Developmental Science, 3, 344-359. doi:10.1111/ 1467-7687.00129

Leslie, A. M. (1982). The perception of causality in infants. Perception, 11, 173-186. doi:10.1068/p110173

Leslie, A. M. (1984). Spatiotemporal continuity and the perception of causality in infants. Perception, 13, 287-305. doi:10.1068/p130287

Leslie, A. M., \& Keeble, S. (1987). Do six-month-old infants perceive causality? Cognition, 25, 265-288. doi:10.1016/S0010-0277(87)80006-9

Lipton, J. S., \& Spelke, E. S. (2005). Preschool children's mapping of number words to nonsymbolic numerosities. Child Development, 76, 978-988. doi:10.1111/j.1467-8624. 2005.00891.x

McDermott, L. C., \& Redish, E. F. (1999). Resource letter PER-1: Physics education research. American Journal of Physics, 67, 755-767.

Michotte, A. E. (1963). The perception of causality. New York: Basic Books.

Muentener, P., \& Carey, S. (2010). Infants' causal representations of state change events. Cognitive Psychology, 61, 63-86. doi:10.1016/j.cogpsych.2010.02.001

Newman, G. E., Choi, H., Wynn, K., \& Scholl, B. J. (2008). The origins of causal perception: Evidence from postdictive processing in infancy. Cognitive Psychology, 57, 262-291. doi:10.1016/j.cogpsych.2008.02. 003

Oakes, L. (1994). Examining in infancy: Does it reflect active processing? Developmental Psychology, 30, 869-879. doi:10.1037/0012-1649.30.6.869

Oakes, L. M., \& Cohen, L. B. (1990). Infant perception of a causal event. Cognitive Development, 5, 193-207. doi:10.1016/0885-2014(90)90026-P

Pauen, S. (1996). Children's reasoning about the interaction of forces. Child Development, 67, 2728-2742. doi:10.1111/j.1467-8624.1996.tb01885.x

Piaget, J. (1955). The child's conception of the world. London: Routledge \& Kegan Paul.

Rakison, D. H., \& Krogh, L. (2012). Does causal action facilitate causal perception in infants younger than 6 months of age? Developmental Science, 15, 43-53. doi:10.1111/j.1467-7687.2011.01096.x

Roth, K. J. (1990). Developing meaningful conceptual understanding in science. In B. F. Jones \& L. Idol (Eds.), Dimensions of thinking and cognitive instruction (pp. 139-176). Hillsdale, NJ: Erlbaum.

Saxe, R., Tenenbaum, J. B., \& Carey, S. (2005). Secret agents: Inferences about hidden causes by 10- and 12-month-old infants. Psychological Science, 16, 995-1001. doi:10.1111/ j.1467-9280.2005.01649.x

Saxe, R., Tzelnic, T., \& Carey, S. (2007). Knowing who dunnit: Infants identify the causal agent in an unseen 
causal interaction. Developmental Psychology, 43, 149-158. doi:10.1037/0012-1649.43.1.149

Schlottmann, A., \& Anderson, N. A. (1994). Children's judgments of expected value. Developmental Psychology, 30, 56-66. doi:10.1037/0012-1649.30.1.56

Schlottmann, A., Ray, E. D., Mitchell, A., \& Demetriou, N. (2006). Perceived physical and social causality in animated motions: Spontaneous reports and ratings. Acta Psychologica, 123, 112-143. doi:10.1016/j.actpsy. 2006.05.006

Shultz, T. R. (1982). Rules of causal attribution. Monographs of the Society for Research in Child Development, 47(1, Serial No. 194).

Siegler, R. S. (1976). Three aspects of cognitive development. Cognitive Psychology, 8, 481-520. doi:10.1016/ 0010-0285(76)90016-5

Sloman, S., Barbey, A. K., \& Hotaling, J. M. (2009). A causal model theory of the meaning of cause, enable, and prevent. Cognitive Science, 33, 21-50. doi:10.1111/j.15516709.2008.01002.x

Sluzenski, J., Newcombe, N., \& Satlow, E. (2004). Knowing where things are in the second year of life: Implications for hippocampal development. Journal of Cognitive Neuroscience, 16, 1443-1451. doi:10.1162/0898929042304804

Spelke, E. S., Philips, A. T., \& Woodward, A. L. (1995). Infants' knowledge of object motion and human action. In D. Sperber, D. Premack, \& A. Premack (Eds.), Causal cognition: A multidisciplinary debate (pp. 44-77). Oxford, England: Oxford University Press.

Straube, B., \& Chatterjee, A. (2010). Space and time in perceptual causality. Frontiers in Human Neuroscience, 4, 28.

Talmy, L. (1985). Lexicalization patterns: Semantic structure in lexical forms. In T. Shopen (Ed.), Language typol- ogy and syntactic description (pp. 57-149). New York: Cambridge University Press.

Talmy, L. (1988). Force dynamics in language and cognition. Cognitive Science, 12, 49-100. doi:10.1016/0364-0213 (88)90008-0

Wilkening, F. (1981). Integrating, velocity, time, and distance information: A developmental study. Cognitive Psychology, 13, 231-247. doi:10.1016/0010-0285(81) 90009-8

Wilkening, F., \& Cacchione, T. (2011). Children's intuitive physics. In U. Goswami (Ed.), The Wiley-Blackwell handbook of childhood cognitive development (2nd ed., pp. 473-496). Chichester, UK: Wiley.

Wolff, P. (2003). Direct causation in the linguistic coding and individuation of causal events. Cognition, 88, 1-48. doi:10.1016/S0010-0277(03)00004-0

Wolff, P. (2007). Representing causation. Journal of Experimental Psychology: General, 136, 82-111. doi:10.1037/ 0096-3445.136.1.82

Wolff, P., Klettke, B., Ventura, T., \& Song, G. (2005). Categories of causation across cultures. In W. Ahn, R. L. Goldstone, B. C. Love, A. B. Markman, \& P. Wolff (Eds.), Categorization inside and outside of the lab: Festschrift in Honor of Douglas L. Medin (pp. 29-48). Washington, DC: American Psychological Association.

Wolff, P., \& Song, G. (2003). Models of causation and the semantics of causal verbs. Cognitive Psychology, 47, 276-332. doi:10.1016/S0010-0285(03)00036-7

Wolff, P., Song, G., \& Driscoll, D. (2002). Models of causation and causal verbs. In M. Andronis, C. Ball, H. Elston, \& S. Neuval (Eds.), Papers from the 37th Meeting of the Chicago Linguistics Society, Main Session (Vol. 1, pp. 607-622). Chicago: Chicago Linguistics Society. 